\title{
Rethinking the psychology of leadership: From personal identity to social identity
}

\section{S. Alexander Haslam, School of Psychology, University of Queensland.}

Stephen, D. Reicher, School of Psychology, University of St. Andrews.

\begin{abstract}
Leadership is an influence process that centers on group members being motivated to reach collective goals. As such, it is ultimately proved by followership. Yet this is something that classical and contemporary approaches struggle to explain as a result of their focus on the qualities and characteristics of leaders as individuals in the abstract. To address this problem we outline a social identity approach that explains leadership as a process grounded in an internalized sense of shared group membership that leaders create, represent, advance, and embed. This binds leaders and followers to each other and is a basis for mutual influence and focused effort. By producing qualitative transformation in the psychology of leaders and followers it also produces collective power that allows them to co-produce transformation in the world. The form that this takes then depends on the model and content of the identity around which the group is united.
\end{abstract}


"I have always regarded myself, in the first place, as an African patriot." Nelson Mandela "I am, if I am anything, an American. I am an American from the crown of my head to the soles of my feet." Theodore Roosevelt.

"Above all, I am a German. As a German I feel at one with the fate of my people." Adolf Hitler

Effective leadership is the ability to influence people in a way that motivates them to contribute to the achievement of group goals. As such, Nelson Mandela, Theodore Roosevelt, and Adolf Hitler were all effective leaders. We may evaluate their various achievements in very different ways (it would be worrying if we did not), but it would be hard to deny that their capacity to mobilize a mass constituency to bring about these achievements - that is, their capacity for leadership — was truly remarkable.

Because leadership mobilizes people and focuses them on the achievement of cherished goals - even where this requires major social change — it is highly prized and a major focus for academic and public debate. In fields as diverse as politics and religion, science and technology, art and literature, sport and adventure, industry and business, leadership is commonly seen as the key process through which people are marshalled to contribute to the collective projects that ultimately make history. In light of this, two key questions have fascinated scholars and commentators for over two millennia: What makes people effective leaders? And, if we discover this, can we train others to be effective leaders themselves?

Answering these questions has spawned an industry so vast that its scale is hard to fathom. For example, although their value has been seriously questioned ${ }^{1}$, there are close to 1,000 different degree courses in leadership in the US alone, and it is estimated that US companies spend around $\$ 14$ bn a year on leadership training. It has also spawned an academic literature that spans multiple disciplines, that uses multiple approaches from laboratory experimentation to historical biographies, and which again is so vast that no-one could digest more than a small fraction of it. The British Library alone holds over 80,000 documents with leadership in their title, including over 15,000 books (of which around 40 are simply called Leadership).

Given all this information and knowledge, it might seem arrogant, if not foolhardy, to suggest that there is a need to fundamentally rethink the nature of leadership or that we require (to cite the title of the book that we recently co-authored with Michael Platow ) "a new 
psychology of leadership" "2. But that is precisely what we do suggest — and what we hope to provide - in this essay. We start by explaining why a new approach is needed. This conviction derives from the fact that classical and contemporary understandings of leadership have been constrained by an individualistic metatheory. This has led researchers and commentators alike to seek the roots of effective leadership within the person of the leader and the ability of the leader to satisfy the personal needs of followers. We then outline our alternative approach which argues, in contrast, that effective leadership is always about leaders and followers seeing themselves as bound together through their joint membership of the same group and working together to satisfy group needs and realize group ambitions.

In short, whereas the existing leadership literature tends almost universally to see the psychology of leadership as an 'I' thing, we will endeavor to show that it is actually a 'we' thing. Where the vast majority of the tracts on leadership write about its psychology in the first-person singular, we argue that it needs to be written in the first-person plural. Leadership, we suggest, can never be 'all about me' (the leader). As our starting quotes from Mandela, Roosevelt and Hitler suggest, ultimately it needs to be 'all about we' — where 'we' enfolds leaders and followers in the same psychological group.

The definition of leadership that we provided in our opening sentence contains at least four important elements that we need to get to grips with before attempting to make headway. First, leadership is a process not a property and it is more akin to a verb than to a noun. Accordingly, it is not something that a person possesses, but rather something that he or she does. Second, leadership can never be something that a person does on his or her own. Precisely because it requires the mobilization of others, it necessarily encompasses other people beyond the leader. This point is made pointedly by Bertolt Brecht in his poem "Questions from a worker who reads"3 " Who built Thebes of the seven gates?", he asks (along with a range of similar questions about the feats of other heroic leaders); "In the books you will read the names of kings. Did the kings haul up the lumps of rock?" Of course the answer is 'No'. Third, this observation speaks to the fact that ultimate proof of leadership is found not within leaders - neither their character, their vision, nor even their actions - but in the followership of those they influence. The point of Brecht's poem is that in the absence of hard work on the part of loyal group members, there can be no leadership to speak of, no leadership book to write. Accordingly, by 
telling us only about leaders, most analyses of leadership conceal from us a key term in the leadership equation. Fourth, it is important not to conflate leadership and a range of other processes with which it is commonly associated. In particular, although leadership is often discussed as a process of power, coercion, or resource management, it is fundamentally about influence. As the social psychologist John Turner put it, it is about power through, rather than power over ${ }^{4}$, others. It is about taking people with you so that they want to follow and do so with enthusiasm, rather than about beating them with a stick (or a carrot) so that they participate grudgingly or only for so long as one has carrots to offer. The mark of leadership, then, is not whether others feel obliged to do your bidding so long as you are standing over them, but whether they will go the extra mile for you, even when you are absent.

In these terms the question that lies at the core of the leadership process is what it is that allows the plans of an individual to be translated into the aims and desires of the mass? What is it that turns one person's vision into a collective mission that directs the energies of tens, thousands, even millions of other people? As we argue in The New Psychology of Leadership, over time researchers have tended to answer this question in one of three broad ways. In the first instance, proponents of a classical approach generally provide answers framed in terms of core qualities that particular individuals possess (or lack). This, we argue, is characteristic of an old psychology of leadership that has relatively few disciples today (at least in academic circles). Building upon this, adherents of a contextual approach supplement such analysis with a consideration of various features of the prevailing social context that either facilitate or else compromise the effectiveness of individual leaders. This approach takes many different forms and is characteristic of what we see as the contemporary psychology of leadership. Finally, as we have already intimated, the new psychology of leadership that we will outline sets out an identity approach. This sees leadership as a group process that centres on a psychological bond between leaders and followers which is grounded in an internalized sense of their common group membership - that is, a sense of shared social identity or 'we-ness'. However, to appreciate what makes this approach new, and what is distinctive and useful about the analysis it affords, we first need to spend some time reflecting on the forms of understanding that it seeks to challenge and move beyond. 
Plato is commonly acknowledged as having provided the first formal analysis of leadership in around 380bc. For him, like Heraclitus before him, true leaders constitute a rare breed of people who are born with a cluster of attributes and qualities that set them apart from the hoi polloi. These include quickness of learning, courage, broadness of vision, and physical prowess. Moreover, because these qualities are so rarely encountered in one person, when they are they need to be nurtured and rewarded. As Heraclitus put it "The many are worthless, good men are few.... One man is ten thousand if he is the best"

Although largely conversational, Plato's analysis provided a narrative framework that has dominated leadership thinking for the last two-and-a-half millennia. Its influence today can be seen in the range of popular texts that proliferate in airport bookstores and that serve to catalogue the distinctive prowess of the leader of the moment — often as 'secrets' to be generously shared with readers. However, the popularity of this approach — and of this literary genre — was cemented in the $19^{\text {th }}$ century through the writings of the Scottish historian and philosopher Thomas Carlyle. His best-selling text On Heroes and Hero Worship 6 declared that "the history of what man has accomplished in this world, is at bottom the History of the Great Men who have worked here".

This thesis of the great man invited everyone from schoolchildren to scholars to see leadership not as the stuff of ordinary mortals but as the stuff of gods, arguing that great leaders' distinctive and exceptional qualities qualified them not only for responsibility and high office, but also for widespread admiration and respect. Today still, it is the exceptional nature of such 'stuff' that is seen to justify the exorbitant salaries routinely awarded to executive leaders. But what precisely are the qualities that are involved? It is when one tries to pin down the details that the problems begin.

Over the years, psychologists have studies an impressive array of candidate variables: everything from conventionalism and confidence to sociability and surgency ${ }^{7}$. Yet whatever the target variable, summary reviews have generally concluded that personal attributes prove rather unreliable predictors of leadership. This is true of the two attributes that have had the most enduring appeal for researchers and commentators alike — charisma and intelligence.

Max Weber's ${ }^{8}$ original definition of charisma refers to "a certain quality of an individual personality by which [a leader] is set apart from ordinary men and treated as endowed with superhuman, or at least specifically exceptional powers or qualities". This definition is therefore 
somewhat ambivalent, referring both a quality that the individual has, and to qualities that he or she is treated as having by "ordinary men". In the work of neo-Weberian leadership theorists like James MacGregor Burns this ambivalence largely disappears and the focus is placed firmly on qualities of the leader - specifically his or her capacity to articulate a group vision, to recruit others to their cause, and to develop close and strong relationships with group members. Yet, as we will discuss in more detail below, despite the fact that research provides fairly solid evidence that successful leaders tend to be transformational in being both visionary and empathic, attempts to root this in the capacities of the individual have largely failed. A key reason for this is that, on their own, vision (however brilliant) and empathy (however authentic) are not enough to guarantee success.

In contrast, the dimension of Weber's formulation which theorists tend to ignore seems more promising. For research shows that perceptions of charisma are critical to the leadership process. Reflecting on the Greek meaning of charisma as a "special gift", Michael Platow and colleagues $^{9}$ thus observe that it is best thought of as a gift that is bestowed on leaders rather than one that is possessed by them. Moreover, in bestowing charisma, followers also commit their energies to the leader. But whether followers bestow charisma is not down to the leader alone. Indeed, at different times and in different places the same leader may be seen as more or less charismatic. This is because perceptions of charisma are a function of the changing social relationship between leaders and followers and, more specifically, of whether the leader represents a group that the followers currently identify with. So, in the context of the primaries, democrats supporting Clinton may not see Obama as charismatic. In the context of the Presidential election, those Clintonite Democrats are more likely to bestow him with charisma. And once President, even non-Democrats may come to see his charismatic qualities.

Despite the fact that the construct of charisma has proved hard to pin down, one might imagine that intelligence would provide researchers greater predictive traction as a result of its proud psychometric heritage. Indeed, a key reason why this has been an important focus for research is that in systematic reviews this typically emerges as the best single predictor of leader success. Yet formal measures of leader intelligence (e.g., IQ scores) still only explain a very small amount of the variance in leader success. In an attempt to improve upon this, considerable energy has gone into refining the analytic construct of intelligence. The upshot is that researchers now tend to argue that it is particular types of intelligence that are especially important for 
leadership — notably either practical intelligence or emotional intelligence. Here again, though, the constructs prove hard to isolate, in part because their form and meaning vary markedly across contexts. In part too, this is because, as with charisma, it is a leader's perceived intelligence that seems to be what really matters and this not highly correlated with formally assessed intelligence. At a broader level, then, what we see is that despite researchers' efforts to keep their (and our) analytic gaze solely on the psychology of leaders, the psychology of followers keeps worming its way into the picture.

In response to the limited predictive power of approaches that focus exclusively on the character of the leader, most contemporary leadership researchers endorse contextual approaches that pay heed to the social environment in which leaders find themselves. Extreme versions suggest that context is everything, and that the character of the individual counts for nothing but, for good reason, theorists and practitioners have found these unconvincing. Accordingly, they tend to embrace contingency models in which context is seen to moderate but not entirely suppress the contribution of the leader.

Standard contingency models essentially construe leadership as the outcome of a 'perfect match' between two core ingredients of the leadership process: the individual leader and the circumstances of the group that he or she leads. There are a very large number of such models, and they constitute the most influential way of thinking about leadership, both in formal academic treatments of the topic and in everyday discourse. In particular, they lend structure and content to a plethora of management and personal development courses that try first to classify individuals as having a particular leadership style and then to train them to identify (or create) situations in which this style will be effective.

The general notion that leadership is the product between contingencies of person and situation makes a lot of sense. Nevertheless, a core problem with standard contingency models is that they treat these two terms as fixed and, most problematically, as having no capacity to shape each other. That is, they tend to neglect the capacity for the social context to be changed by leaders or for leaders to be changed by the social context. Yet if one reflects for just a moment on the leadership of Mandela, Roosevelt and Hitler, it is clear that in each case the leader and their social context both exerted a powerful influence upon each other. Indeed, as we argued above, 
the reason why leadership fascinates us is precisely because of this potential for transformation. It therefore makes little sense to subscribe to a framework that allows no space for change.

Even more fundamentally, however, standard contingency models generally ignore the most important element of the leader's context - namely followers. And even when the importance of followers is acknowledged, such approaches fail to build their perspective into the analysis. Does it matter whether followers see the leader as the right person for the situation? Do these perceptions of fit affect the support that followers give to the leader? Yes it does — and such considerations gain importance as the leadership stakes become higher. Moreover, the fact that the followers' perspective is ignored in most contingency models goes a long way to explaining why empirical support for them is mixed at best and why it becomes weaker the further away from the laboratory one gets.

More recently, the conceptual and empirical failings of standard contingency models have led to new transactional and transformational approaches that both make followership a key part of the story. These models mark an important departure (though, as we shall see, not a complete departure) from the traditional individualist metatheory of leadership research. For they treat leadership as a social relationship between leaders and followers rather than as something to be sought within the leader alone.

Transactional approaches view leadership as a form of social exchange in which followers work to realize a leader's vision to the extent that they believe that the leader is working for them in return and that there is equity between what they put in and what they get out of the process ${ }^{10}$. For all their appeal (not least in pointing to the inefficiency of organizations which provide excessive remuneration to those at the top while offering meagre wages to those at the bottom), these approaches have important limits. In particular, they presuppose that the terms of the exchange are set. That is, leaders can only provide people with the things they already reward rather than change what they count as a reward. But, as we have already argued, one of the key accomplishments of leadership is to transform the things we care about and to make us concerned about things we previously ignored - whether that be particular commodities, equality, environmental sustainability or whatever. Transactional approaches also presuppose that actors are motivated entirely by personal gain (one of the ways they fail to break with traditional individualism). Thus they reduce followership to the question "What's in this for me?”. But this misses another key accomplishment of leadership: the ability to transform 
followers' focus on individual benefit into a concern for the greater good. In short, it is generally only when leaders and followers prove willing and able to rise above their personal self-interest — and to think about "What's in this for us?" - that things go well for their group.

The latter critique provided important impetus for the development of transformational approaches. These insist that effective leadership is based on more than just mercantile arrangements in which mutual obligation flows from interpersonal account keeping. Instead, what makes the process remarkable is precisely its capacity to allow people to embrace a bigger vision of their place in the world, to work for the collective good, and thereby scale new practical and moral heights ${ }^{11}$.

We fully endorse this critique. In particular, we agree that people are able to impact the world to the extent that they are able to work together as members of a group. Such an approach marks a revolutionary turn in the study of leadership. Likewise, it requires a revolutionary turn in the way that we conceptualise human psychology and, more particularly, concepts like identity and interest. Yet the limitation to transformational leadership models is that they cannot fully deliver on their promise because they still don't fully break with psychological individualism.

Thus, even if they accept that leaders can transform the motivations of followers, transformational approaches still assume that the highest state of motivation and morality is characterized by individual autonomy ${ }^{12}$. And even though they root the leader's ability to be transformational (that is, their charisma) in the perceptions of followers, they still assume that followers focus on fixed individual abilities and qualities of the leader (as considerate, intelligent or whatever). They therefore miss the point - as the examples of Mandela, Roosevelt and Hitler attest - that in different contexts what makes people invest in a leader is very different.

What made these leaders so effective was precisely their sensitivity to social context. What each did was to envision and become emblematic of a particular group of people in a particular place at a particular point in time. This allowed them to mobilize those people to transform the material landscape of society. And this is not just true of Mandela, Roosevelt and Hitler, but of all leaders. This points to a simple but fundamental observation: that leadership is not just about leaders and followers, but about leaders and followers within a specific social group. This observation takes us into new theoretical territory. For it requires us to articulate an analysis of leadership within a broader understanding of basic group processes. 
Although our review has focused on the limitations of classical and contemporary approaches, these nonetheless provide valuable lessons. In particular, they help us understand what it is that an adequate theory of leadership needs to explain. Five features in particular are important:

1. leadership varies in form across social contexts;

2. followers' perceptions of leadership are critical but also vary across contexts;

3. leadership involves leaders and followers motivating and influencing each other;

4. leadership transforms not only the world but the also the psychology of the leaders and followers who bring transformation about; and

5. leaders and followers are bound together by being part of a common group

The key contention of the new psychology of leadership is that, by taking this last lesson seriously - by addressing leader's and follower's conceptions of themselves and each other as group members - we are in a position to explain the previous four. To this end, we draw on the social identity tradition in social psychology, precisely because it uses people's understandings of their own group membership, and that of others, as the starting point for understanding processes within and between social groups ${ }^{13,14}$.

This tradition proposes that human beings have the capacity to define themselves in collective terms (e.g. "us Democrats". "us social scientists") as well as in individual terms (e.g. "myself as a thoughtful person'), that collective (or social) identities are every bit as real and important to us as individual (or personal) identities, and that the psychological understandings that flow from social identification are qualitatively distinct from those which flow from personal identity. That is, the psychology of 'we and they' cannot be assimilated to the psychology of 'I and me' (the province of most psychology theory), not least because our relations with others are fundamentally transformed once we define ourselves and others in collective terms. So, when we perceive another person to share the same social identity as us (that is, to be part of our psychological ingroup) we see them as part of our self rather than as 'other'. In order to see why this is critical for the analysis of leadership it is helpful to flesh out four key points which emerge from social identity theorizing and research.

First, it is apparent that when (and to the extent that) people define themselves in terms of a particular group membership they are motivated to see that ingroup as positively distinct from other outgroups. That is, as far as possible, they want to see 'us' as different to, and better than, 
'them'13. In these circumstances too, what matters is not a person's sense of how they are doing as individuals but the perceived standing of the group as whole. For example, if a baseball player defines themselves as a member of a particular team, what matters most in a play-off tournament is not winning man of the match but winning the game.

Second, at the same time, it is clear that the process of coming to define the self in terms of a particular social identity is always meaningfully bound up with social context. In particular, it depends on whether a given group membership has been a basis for our self-definition in the past (so that it is accessible) and whether it allows us to make sense of our place in the situation that confronts us (so that it is fitting) ${ }^{15}$. For example, it makes more sense to define oneself as a Democrat (and hence to delight in a Democratic election victory) if one has been a long-term supporter of the party and is watching the election results than if one is watching a baseball game.

Third, when we define ourselves in terms of social identity it is apparent that this is a basis not only for perception but also for behavior. If we see ourselves as Democrats, we don't just see the world differently to supporters of other parties or to people for whom politics appears pointless (e.g., so that we have a very different appreciation of a Democratic victory), but we also behave differently. We go to particular meetings, we support particular candidates, we cheer particular events - and we also enact and share these experiences with particular people (even to the extent of hugging complete strangers as 'our' President is elected, if that stranger is wearing the same blue badge as us). As an extensive experimental literature has confirmed ${ }^{16}$, social identity is thus the basis for a range of key social and organizational processes including social connection, communication, coordination, cooperation. That is, we feel more connected to ingroup than to outgroup members, we trust and respect them more, we are more concerned for them, we communicate more and better with them, we are more likely to help and work with them. All in all, social identity is what underpins and indeed makes possible ${ }^{17}$ all forms of group behavior.

More critically still, for present purposes, social identity is also the basis for social influence processes. Thus, when people define themselves in terms of a given social identity they seek both to discover what being a member of that group entails and then to act in ways that accord with this. But in an uncertain and changing world, it is not always clear how one should react, and so we look to guidance from others as to what is appropriate. But who do we turn to, 
and when there are multiple voices advocating multiple responses, which do we attend to and which do we ignore? The obvious answer is that we turn to fellow ingroup members. For if we share social identity with them, and hence share common perspectives and values, we should expect to agree with them, at least on issues of relevance to the group. So, when it comes to the question of how to respond to a matter of current political import, as Democrats we are most likely to turn to fellow Democrats.

However, given the choice, we wouldn't turn to just any old group member. The more we see someone as knowledgeable about the group culture, as consistently expressing in their pronouncements and their actions those norms and values which make our group distinctive from other groups - in technical terms, the more we see them as prototypical of the group - the more we will pay heed ${ }^{18}$, the more we will follow what such people say, and the more effort we will put into supporting their proposals ${ }^{19}$.

This is, of course, an implicit theory of leadership (even if the original work on group prototypicality and social influence did not use the term). We have turned it into an explicit theory with three core premises.

The first premise of the new psychology of leadership is that effective leaders (those who can influence and harness the energies of followers) need to be seen to be representative of a shared ingroup. This is true in two senses. One, that we have already discussed, is that leaders need to be seen as being of the group. They must instantiate what the group stands for and, as our opening quotations attest, it must be clear that they are a group member before all else.

It is important, at this point, to pre-empt a potential confusion. In arguing that leaders need to be prototypical, we are not suggesting that they are typical in the sense of being average group members $^{20}$. Rather they stand for all the qualities which we ascribe to our group: they may have to be seen as brilliant and humble and brave and self-effacing, if that is how we see our collective selves. To be prototypical is to be extraordinary, not to be average. Or rather, because being influential depends upon the way one is perceived by other group members, to be seen as prototypical is to be seen as extraordinary. Indeed, studies show that those who are seen as prototypical are seen to be endowed with that most elusive and most 'magical' of all leadership ingredients: charisma9 ${ }^{9}$.

The second sense of being representative is that leaders need to be seen as acting for the group. Indeed one of the things that is most toxic to leadership effectiveness is the perception 
that one is either acting for oneself or, even worse, for an outgroup. That explains, perhaps, why would-be leadership contenders must always be seen as reluctant candidates, not seeking power for themselves but being entreated to take on the burdens of office. It also explains why Cincinnatus - who came from retirement to save Rome and, once successful, returned back to obscurity - is often held up as a paragon of good leadership. Certainly, evidence suggests that where leaders are seen as promoting their own agenda or enrichment, their charisma rapidly evaporates $^{21}$. Witness, for example, how Tony Blair is now regarded by many of those who once revered him.

In this way we see that key qualities of leadership — like charisma — are not qualities of the leader but are rooted in the relationship between the leader and group identity. This in turn allows us to understand why the qualities that define leadership vary from group to group and context to context. The qualities that made Mandela prototypical of the South African liberation movement, which made Roosevelt prototypical of progressive Republicanism, and Hitler prototypical of Nazi Germany are evidently different. But in each case the relationship between the individual and the social category was the same.

At this point, the attentive reader may object that we are open to the self-same criticism we have (more than once) made of others. That is, if effective leaders need to have qualities that match the distinctive qualities of the group, then there is no room for creativity or transformation. The leadership process becomes entirely passive as people simply wait for circumstances to hoist the mantle of prototypicality on their shoulders. This criticism would be warrented if social identity was something fixed or taken for granted. But it isn't. Identity is an eminently moveable feast and one of the key features of effective leadership is the ability to take advantage of this. Hence, the second premise of the new psychology of leadership is that effective leaders need to be entrepreneurs of identity. That is, they need to be able to construe (and reconstrue) what the group is, who they themselves are, and what they advocate, so as to place all in alignment.

By way illustration, we can compare the leadership of two US Presidents: Franklin Delano Roosevelt and John F. Kennedy. FDR was struck down in his early adulthood with infantile paralysis (thought at the time to be polio). This was believed to be catastrophic for his political aspirations because it undermined those Platonic qualities considered critical for leadership: virility, energy, physical prowess. In particular, when he proposed a train tour to 
support his 1934 Presidential campaign, advisors begged him not to present his broken body before the electorate. But he did. In town after town, he laboriously dragged himself from train to podium. Then he spoke of America as a country with the ability and the will to overcome economic paralysis and to flourish again. It was a message articulated most famously in his inauguration speech: "This great Nation ... will revive and will prosper.... We have nothing to fear but fear itself - nameless, unreasoning, unjustified terror which paralyses needed efforts to convert retreat into advance".

How different this was from JFK, who was also afflicted by a debilitating illness (Addison's disease, leading to a crumbling of the spine). But his narrative of America was as a young vibrant nation breaching a new frontier. He not only hid his disability, but at his own inaugural, where all around wore warm hats, he insisted on showing his full head of hair and declared "the new generation offers a leader".

This performative dimension to leadership can be taken a step further. Thus, leadership is not just about how the leader acts, but also how the leader shapes the performance of followers. For in order to make their versions of shared identity compelling they need to make them real. Obviously, a critical part of this is success in enacting policies that embed group values in social reality. But another, perhaps under-appreciated part, is the use of ritualized performances celebrations, commemorations, festivals, rallies and so on - in which people are encouraged to act out the leader's vision of group values. Accordingly, the third premise of the new psychology of leadership is that effective leaders need to be impressarios of identity. This involves choreographing groups and group life in ways that actualize identity through lived experience.

To illustrate this point, one can reflect on Leni Riefenstahl's infamous film of the 1934 Nazi Nuremburg rally, Triumph of the Will. This begins with Hitler's plane descending through the clouds, casting the shadow of a cross on the expectant masses waiting below. Hitler then walks through the rigorously ordered, serried ranks of the faithful before ascending to a platform in front of them and above them. The performance, of which the masses are an essential part, creates the Nazi vision of a Volksgemeinshaft - a horizontal, disciplined, ethnic community combined with the Führerprinzip - a rigidly vertical form of political authority ${ }^{21}$. Indeed, the extent to which the performance aimed to actualize group values of hardness and order is exemplified by the care with which Albert Speer chose the materials used in the construction of the Nuremberg arena: granite and old, hard German oak. 
In the process of summing up our analysis, it is worth emphasizing three significant points that emerge from the social identity approach to leadership. All relate to problems that arise from endorsing too narrow an understanding of leadership - problems that have routinely beset the classical and contemporary approaches that we seek to move beyond.

The first is that, when it is effective, leadership can never be the exclusive preserve of leaders. In particular, it is apparent that acts of identity entrepreneurship and impresarioship are too demanding in scale for them to be performed only by those in positions of formal authority. Leaders thus need loyal lieutenants to engage in these processes but they also need ordinary group members to do the same. Indeed, much of the power of a social identity analysis is that it explains not only how leaders are able to be creative, but also how followers are too - so that they not only "haul up the lumps of rock" (as Brecht put it), but also do so in imaginative and generative ways. In these terms, the transformational power of social identity is that it is not simply a source of creative leadership but also of the engaged followership ${ }^{22}$ upon which its success depends.

Relatedly, a second point is that leadership — and the processes of identity building that underpin it - can never be exclusively perceptual or rhetorical. It must also be material. To be sure, leaders need to talk the talk of identity and mobilize followers around a collective sense of "who we are" and "what we are about". However, this alone is not sufficient to sustain those followers' enthusiasm in the long run. Instead, social identity is ultimately only of use to the extent that it allows group members to create a better future for their group. Accordingly, if collective mobilization fails to translate a definition of social identity into consonant forms of reality, then that definition - and those leaders who advance it - will fall by the wayside. Yet where, and for so long as, mobilization does succeed in creating positive realities that reflect a given definition of identity, then that definition, and the leaders who help to advance and embed it, will enjoy considerable support. In these terms, then, the X-factor that Mandela, Roosevelt and Hitler all had in common was that they were responsible (or seen to be responsible) for initiating and developing identity structures that allowed a particular model of "us" to be lived out and translated into material change in the world.

This, though, leads on to a final point about the dangers of imagining that leadership is an exclusively positive process. The trap here is that precisely because our own leadership and that 
of those we follow is an expression of a worldview that we believe to be right (a belief that is validated by our fellow ingroup members), we are generally inclined to see leadership as an inherently virtuous process. Indeed, this inclination is cemented within social and organizational science more generally in the form of a strong, usually implicit, assumption that leadership is an unalloyed good (which is why the leadership industry is so vast). Yet although we have argued that the identity processes that underpinned the success of leaders like Mandela, Roosevelt and Hitler were essentially the same, we chose to focus on these three figures to make it clear that our analysis is explanatory rather than normative. That is, the model of identity leadership that we have presented seeks to understand what makes leadership effective not what makes it good.

The question of what makes leadership normatively good or bad, we suggest, is a matter of identity content and of identity process. When it comes to identity content, the way in which group boundaries and the group values are defined is critical. Contrast the Nazi definition of German identity with Mandela's definition of South African society. As the Nazis saw it: "What is the first commandment of every National socialist?... Love Germany above all else and your ethnic comrade [Volksgenosse] as yourself"23. As Mandela saw it (in his famous 1964 speech from the dock): "During my lifetime I have dedicated myself to this struggle of the African people. I have fought against white domination, and I have fought against black domination. I have cherished the ideal of a democratic and free society in which all persons live together in harmony and with equal opportunities. It is an ideal which I hope to live for and to achieve. But if needs be, it is an ideal for which I am prepared to die" ${ }^{24}$. The one proposes an ethnically exclusive definition of identity, the other proposes a racially inclusive version. The one values love for the category but hostility to those without. The other values harmony and equality between peoples. The one facilitated genocide, the other ultimately prevented racial war.

Regarding the issue of identity process, here the issue concerns the balance between leaders and followers in terms of who is entitled to define "who we are"". This lies at the root of questions of political authority. This is at its clearest in religious contexts where there is a sacred text and authority lies in the hands of those who are allowed to interpret that text: the clergy alone, the clergy with congregational participation, or the congregation facilitated by the clergy. We would argue that similar considerations extend into secular politics and that one can identify a continuum from democratic leadership (where leaders guide a collective conversation about "who we are") to hierarchical leadership (where leaders claim special access to the definition of 
group identity but don't exclude the participation of the population) to authoritarian leadership (where leaders claim to so embody the group that any criticism of them is seen as an attack on the group).

These are, of course, ideal types and we do not suggest one can easily map particular leaders onto particular types. Nonetheless, this framework may be helpful in allowing us to identify the signs of creeping authoritarianism and nipping it in the bud. In this way, although the new psychology of leadership is intended primarily to offer an analytic approach, it can, we hope, be directed to democratic and inclusive normative ends. At the very least, it alerts us to the power of identity as a leadership tool and to the need to consider carefully the ways in which that tool is fashioned and wielded. 


\section{Notes}

${ }^{1}$ Kellerman, B. (2012). The end of leadership. New York: Harper Collins.

${ }^{2}$ Haslam, S. A., Reicher, S. D., \& Platow, M. J. (2011). The new psychology of leadership: Identity, influence and power. London and New York: Psychology Press.

${ }^{3}$ Brecht, B. (1935/1976). Poems 1913-1956 (E. Anderson et al., trans). London: Methuen.

${ }^{4}$ Turner, J. C. (2005). Examining the nature of power: A three-process theory. European Journal of Social Psychology, 35, 1-22.

${ }^{5}$ Kahn, C. H. (1981). The art and thought of Heraclitus. Cambridge: Cambridge University Press. p.57

${ }^{6}$ Carlyle, T. (1840). Heroes and hero worship. London: Harrap. p.5

${ }^{7}$ Mann, R. D. (1959). A review of the relationship between personality and performance in small groups. Psychological Bulletin, 56, 241-270.

${ }^{8}$ Weber, M. (1921/1946). The sociology of charismatic authority. In H. H. Gerth \& C. W. Milles (trans., Eds.), Max Weber: Essays in sociology (pp. 245-252). New York: Oxford University Press. p.359

${ }^{9}$ Platow, M. J., van Knippenberg, D., Haslam, S. A., van Knippenberg, B., \& Spears, R. (2006). A special gift we bestow on you for being representative of us: Considering leader charisma from a self-categorization perspective. British Journal of Social Psychology, 45, 303-320.

${ }^{10}$ Hollander, E. P. (1995). Organizational leadership and followership. In P. Collett \& A. Furnham (Eds.), Social psychology at work: Essays in honour of Michael Argyle (pp. 69-87). London: Routledge.

${ }^{11}$ Burns, J. M. (1978). Leadership. New York.

${ }^{12}$ Ellemers, N., De Gilder, D., \& Haslam, S. A. (2004). Motivating individuals and groups at work: A social identity perspective on leadership and group performance. Academy of Management Review, 29, 459-478.

13 Tajfel, H., \& Turner, J. C. (1979). An integrative theory of intergroup conflict. In W. G. Austin \& S. Worchel (Eds.), The social psychology of intergroup relations (pp. 3347). Monterey, CA: Brooks/Cole.

14 Turner, J. C., Hogg, M. A., Oakes, P. J., Reicher, S. D., \& Wetherell, M. S. (1987). Rediscovering the social group: A self-categorization theory. Oxford: Blackwell.

${ }^{15}$ Oakes, P. J., Haslam, S. A., \& Turner, J. C. (1994). Stereotyping and social reality. 
Oxford: Blackwell.

${ }^{16}$ Haslam, S. A. (2001). Psychology in organizations: The social identity approach. London: Sage.

17 Turner, J. C. (1982). Towards a cognitive redefinition of the social group. In H. Tajfel (Ed.), Social identity and intergroup relations (pp. 15-40). Cambridge: Cambridge University Press. (p.21)

${ }^{18}$ Hogg, M. A., \& van Knippenberg, D. (2004). Social identity and leadership processes in groups. Advances in Experimental Social Psychology, 35, 1-52.

${ }^{19}$ Haslam, S. A., \& Platow, M. J. (2001). The link between leadership and followership: How affirming a social identity translates vision into action. Personality and Social Psychology Bulletin, 27, 1469-1479.

${ }^{20}$ Steffens, N., Haslam, S. A., Kessler, T., \& Ryan, M. K. (2013). Leader performance and prototypicality: Their inter-relationship and impact on leaders' identity entrepreneurship. European Journal of Social Psychology, 43, 606-613.

${ }^{21}$ Brown, A. (2014). The myth of the strong leader: Political leadership in the modern age. London: Bodley Head.

${ }^{22}$ Reicher, S. D., Haslam, S. A., \& Smith, J. R. (2012). Working towards the experimenter: Reconceptualizing obedience within the Milgram paradigm as identification-based followership. Perspectives on Psychological Science, 7, 315-324.

${ }^{23}$ Koonz, C. The Nazi Conscience. Harvard: Harvard University Press (p.7).

${ }^{24}$ Mandela, N. (1990). The struggle is my life. Bombay: Popular Prakashan. (p.217) 